\title{
Clostridium difficile isolated from faecal samples in patients with ulcerative colitis
}

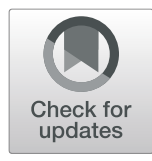

Parisa Shoaei ${ }^{1}$, Hasan Shojaei ${ }^{2}$, Mohammad Jalali ${ }^{3}$, Farzin Khorvash ${ }^{1 *}$, Sayed Mohsen Hosseini ${ }^{4}$, Behrooz Ataei $^{5}$, Bahareh Vakili ${ }^{6}$, Fatemeh Ebrahimi ${ }^{7}$, Hossein Tavakoli ${ }^{8}$, Zahra Esfandiari ${ }^{9}$ and J. Scott Weese ${ }^{10}$

\begin{abstract}
Background: Ulcerative colitis (UC) is an inflammatory bowel disease (IBD) that is widely identified worldwide. This study aimed to investigate the phenotypic characterization and molecular typing of Clostridium difficile isolates among patients with UC at an inflammatory bowel disease clinic in Iran.

Methods: In this cross-sectional study, conducted from April 2015 to December 2015, 85 UC patients were assessed for C.difficile infection (CDI). C. difficile isolates were characterized based on their toxin profile and antimicrobial resistance pattern. Multi-locus sequence typing analysis (MLST) and PCR ribotyping were performed to define the genetic relationships between different lineages of toxigenic strains.

Results: The prevalence of $C$. difficile isolates was 31.8\% (27/85) in patients, of those 15 patients (17.6\%) had CDI. Three different sequence types (STs) identified based on MLST among the toxigenic isolates, that is ST54 (33.3\%), ST2 (53.3\%), and ST37 (13.6\%).

C. difficile strains were divided into four different PCR-ribotypes (012, 014, 017 and IR1). The most common ribotype was 014 accounting for $48.3 \%$ (7/15) of all strains. The strains isolated during the first episode and recurrence of CDI usually belonged to PCR ribotype 014 (ST2). A high rate of CDI recurrence $(14.1 \%, 12 / 85)$ experienced in UC patients. Colonization of the gastrointestinal tract with non-toxigenic $C$. difficile strains was frequent among patients with mild disease.

All C. difficile isolates were susceptible to metronidazole, and vancomycin, 86 and $67 \%$ of isolates were resistant to clindamycin and erythromycin respectively. There was no correlation between the toxin type and antibiotic resistance $(p>0.05)$.

Conclusion: Overall CDI is rather prevalent in UC patients. All patients with CDI experienced moderate to severe disease and exposed to different antimicrobial and anti-inflammatory agents. Close monitoring and appropriate management including early detection and fast treatment of CDI will improve UC outcomes.
\end{abstract}

Keywords: Clostridium difficile, Ulcerative Colitis, IBD patients, PCR-Ribotyping, Multilocus sequence typing

\section{Background}

Clostridium difficile, a gram-positive anaerobic bacterium, is the leading cause of pseudomembranous colitis, nosocomial and antimicrobial-associated diarrhea [1, 2]. Increases in morbidity, mortality and relapse rates, along with the emergence of community-associated disease, have heightened concern about CDI internationally. The pathophysiology of $C$. difficile involves colonization of

\footnotetext{
* Correspondence: 2018khorvash@gmail.com

'Nosocomial Infection Research Center, Isfahan University of Medical

Sciences, Isfahan, Iran

Full list of author information is available at the end of the article
}

the intestinal tract and toxin production. Toxin A encoded by $t c d A$, and toxin $\mathrm{B}$ encoded by $t c d B$, are the most important recognized virulence factors, while another toxin, CDT (encoded by $c d t A / c d t B$ ) is present in a subset of toxigenic strains [3, 4].

Various molecular typing methods have been applied to characterize outbreaks and describe endemic CDI and $C$. difficile colonization. Hypervirulent clones such as ribotype 027 and to a lesser degree ribotype 078 have been involved in severe nosocomial outbreaks of CDI [3, 4]. Multilocus sequence typing analysis (MLST) for C. difficile has also been developed to study clonal relations of the

(C) The Author(s). 2019 Open Access This article is distributed under the terms of the Creative Commons Attribution 4.0 International License (http://creativecommons.org/licenses/by/4.0/), which permits unrestricted use, distribution, and 
bacterial populations $[5,6]$. Recent MLST studies on $C$. difficile have focused on human isolates, animal and food strains $[6,7]$.

Ulcerative colitis (UC) is an inflammatory bowel disease (IBD) that is widely identified worldwide. The clinical outcome of UC is highly variable from mild to an aggressive disease that may require a colectomy [8]. Determining risk factors that influence disease course is an important clinical issue. Many studies have shown that UC patients have a high risk of Clostridium difficile infection (CDI) when compared with healthy population or individuals with Crohn's disease $[9,10]$. CDI can worsen the prognosis of recently diagnosed patients with UC, increasing the risk of colectomy, postoperative complications, and death $[8,11]$. There is a report indicating that the incidence of CDI in IBD patients in a nationwide data analysis doubled from 2.66 to $5.12 \%$ over a 7 years period in the USA $[12,13]$. Potential risk factors for acquiring CDI in IBD patients are similar to those in the non-UC population and include the use of broad-spectrum antimicrobial drugs, especially fluoroquinolones, age over 65, chemotherapy and hospitalization [13-16]. In addition, decreased intestinal microbial diversity along with an inadequate immune response may play a causative role in the development CDI. Moreover, diagnosis and appropriate management of CDI in the setting of IBD is difficult due to overlap symptomatology, as both infection and disease flare present with similar symptoms of elevated inflammatory biomarkers and diarrhea [17]. There is a strong recommendation that all patients with IBD, hospitalized with disease flare and patients who develop diarrhea in the setting of quiescent disease must undergo testing for CDI [18].

Data on the prevalence of CDI in UC patients have come from developed countries. Since limited information is available on the occurrence of CDI in UC patients in Iran or other Middle Eastern countries, we carried out this study to investigate the prevalence of CDI in patients with $\mathrm{UC}$ and, to characterize C.difficile isolates in UC patients.

\section{Methods}

This was a cross-sectional study conducted on ulcerative colitis patients referred to the Isfahan University of Medical Sciences inflammatory bowel disease clinics in Isfahan, Iran between April 2015 and December 2015. Patients between 18 and 65 years old with a documented diagnosis of ulcerative colitis were included. Patients with chronic obstructive pulmonary disease, severe liver dysfunction, end-stage renal disease, malignancy, and immunodeficiency syndromes were excluded. The demographic information and potential risk factors of patients such as age, gender, previous surgery, all drugs used by patients and antibiotic treatment within 8 weeks before the time of $C$. difficile detection were recorded. Diagnosis of UC was based on clinical signs and symptoms combined with disease activity, histologic, endoscopic, and radiological results according to the Porto criteria and Truelove-Witts activity index [19]. The moderate or severe disease was defined as symptomatic UC (fever, blood in the stool, number of stool specimen, hemoglobin level and elevation of Erythrocyte sedimentation rate $(>30)$ and with a Truelove-Witts score greater than 4 points) [20-22].

Clostridium difficile infection most commonly defines as the presence of $C$. difficile toxin in the context of characteristic clinical manifestations including diarrhea and abdominal pain in contrast with $C$. difficile colonization in healthy individuals. Because of UC and CDI symptoms overlap we described CDI as three or more daily bowel movements for a period of at least 48 $\mathrm{h}$ in the setting of previously quiescent UC disease [23].

CDI recurrence was described based on looser bowel movement numbers or developed new signs of severe colitis that last for more than two days [13].

A total of 170 fecal samples were collected from 85 UC (2 samples per patient) ranging in age from 20 to 65 years. The first set of samples were collected on May 2015 and the second set was taken about 2-3 months later. Stool samples collected in sterile collectors and immediately transferred into the laboratory of Infectious Diseases and Tropical Medicine Research Centre, Isfahan, Iran and preserved at $-70{ }^{\circ} \mathrm{C}$ during the analysis period. Patients with UC were treated with anti-inflammatory and steroids drugs in accordance with clinical protocols. Patients with CDI $(t c d A$ and or $t c d B$ positive isolates) treated with metronidazole for 2 weeks. Stools specimens were screened for the presence $C$. difficile. Stools specimens were analyzed for the presence of other enteropathogenic organisms (E. coli, Salmonella spp, Shigella spp, and Campylobacter jejuni).

\section{Clostridium difficile culture}

Selective, enrichment culture was performed [20]. Briefly, about $2 \mathrm{~g}$ of stool was inoculated into $10 \mathrm{ml}$ of $C$. difficile moxalactam norfloxacin (CDMN) broth culture. The cultures were incubated in an anaerobic jar in an atmosphere composed of $86 \% \mathrm{~N}_{2}, 7 \% \mathrm{H}_{2}$, and $7 \% \mathrm{CO}_{2}$ at $37^{\circ} \mathrm{C}$ for $48 \mathrm{~h}$ by using an Anoxomat system (MART Microbiology B.V., Drachten, Netherlands). One $\mathrm{mL}$ of enriched broth was mixed thoroughly with an equal volume of $95 \%$ alcohol and held at room temperature for $30 \mathrm{~min}$. The tubes were centrifugated at $2500 \mathrm{~g}$ for $5 \mathrm{~min}$ and the alcohol supernatant was decanted. The pellets were inoculated by a swab onto the $C$. difficile moxalactam norfloxacin agar (CDMN) and incubated anaerobically for $48 \mathrm{~h}$ at $37 \mathrm{C}^{\circ}$. Negative cultures remained in the 
incubator for up to 7 days. The colonies characterized with $2-3 \mathrm{~mm}$ in diameter, $p$-cresol odor, ultraviolet fluorescence (365 nm), typical Gram stain morphology, positive malachite green for spore and positive biochemical reactions such as L-proline aminopeptidase test (Prodisk, Remeb, Lenexa, KS, USA) were identified as $C$. difficile and stored at $4{ }^{\circ} \mathrm{C}[4,24]$.

\section{Molecular identification of $C$. difficile}

DNA extraction was performed using the modified Pitcher et al., procedure (1989). Briefly, Cultures of $C$. difficile strains grown in $\mathrm{BHI}$ broth were centrifuged and cells were treated with lysozyme $(50 \mathrm{mg} / \mathrm{ml})$ and resuspended in TE (Tris, $10 \mathrm{mM}$; EDTA, $50 \mathrm{mM}$; pH 8.0). Guanidium thiocyanate and sarkosyl were added to the mixture for protein denaturation [25, 26]. All isolates were screened for the presence of the genes encoding toxin $\mathrm{A}$ and $\mathrm{B}(t c d A$ and $t c d B)$, binary toxins ( $c d t A$, $c d t B$ ) and triose phosphate isomerase (tpi) [24, 27]. Multiplex PCR amplification performed in a thermocycler (Eppendorf, Germany). The $25 \mu \mathrm{l}$ reaction mixture included $1 \times$ PCR buffer, $250 \mu \mathrm{M}$ of each dNTPs, $10 \mathrm{pM}$ of primers $(t c d A, t c d B), 5 \mathrm{pM}$ of primers $(t p i), 1 \mathrm{U}$ Taq polymerase (Cinna Gene, Iran) and $100 \mathrm{ng}$ of DNA. Amplification was carried out in a touchdown protocol $[4,24,27]$. C. difficile ribotype 027 was used as positive control for molecular and microbiological analysis. $C$. perfringens 450 MTCC (Microbial Type Culture Collection) served as the negative control [28].

\section{Disk diffusion antimicrobial susceptibility testing}

The following antimicrobial susceptibility disks were used for antimicrobial susceptibility test metronidazole $(5 \mu \mathrm{g})$, vancomycin $(30 \mu \mathrm{g})$, clindamycin $(2 \mu \mathrm{g})$, moxifloxacin $(5 \mu \mathrm{g})$, fusidic acid $(10 \mu \mathrm{g})$, erythromycin $(15 \mu \mathrm{g})$, rifampicin $(5 \mu \mathrm{g})$, (Rosco Diagnostica A/S NEO-SENSITABS TM, Denmark). All tests were performed on Brucella Blood Agar containing vitamin $\mathrm{K} 1(1 \mu \mathrm{g} / \mathrm{mL})$, haemin $(5 \mu \mathrm{g} / \mathrm{mL})$ and $5 \%$ defibrinated sheep red blood cells [29]. The zone diameters were read at $100 \%$ inhibition. For the preparation of inoculum, inoculation, and incubation we followed the 15-15-15-min rule as recommended by the European Committee on Antimicrobial Susceptibility Testing (EUCAST) (http://www.eucast.org). Strains were deemed susceptible or resistant to the test antibiotic according to documented pharmacological breakpoint values [30]. The antimicrobial agents tested were selected because of the emergence of reduced susceptibility.

\section{Multilocus sequence typing (MLST)}

Multilocus sequence typing (MLST) with seven housekeeping genes $(a d k, \operatorname{atp} A, d x r, \operatorname{gly} A, \operatorname{rec} A, \operatorname{sod} A$, and tpi) was performed as described by Griffiths et al., 2010 [5]. The amplified products were sequenced by Bioneer
Corporation in South Korea. The DNA sequences of the 7 genes were submitted to the MLST database to determine the sequence type (ST).

\section{PCR-Ribotyping analysis}

Isolates were subjected to PCR-ribotyping as described by Bidet et al. [12]. Interpretation of ribotyping results was performed by visual identification. Ribotype patterns were designated by internal nomenclature. Reference strains of ribotype 027 and 078 were available for comparison.

\section{Statistical methods}

Data were presented as count and percentage. A first univariate logistic regression model was fitted on each independent variable, and a multivariate regression model with adjustment for the effects of other covariates was used. Variables that were significant in univariate models $(p<0.05)$ were entered into the multivariate model. Selection of variables in the multivariate model was based on a stepwise procedure. We estimated Odds Ratios (ORs) and 95\% confidence intervals for each of clinical factors using logistic regression models. All probabilities were two-tailed and a $p$-value of $<0.05$ defined statistically significant. Statistical analysis was performed using the statistical software SPSS, version 16.

\section{Results}

Out of 85studied patients, 27 C. difficile isolates (31.8\%) were recovered from their stool specimens, including 15 (17.6\%) with CDI (toxigenic isolates carried one or both $t c d A$ and $t c d B$ genes) and $70(82.4 \%)$ with non-CDI. The toxigenic isolates detected in both stools samples of patients with CDI. None of the specimens were positive for toxin A alone or binary toxin. Salmonella spp, Shigella spp, E. coli, and Campylobacter jejuni were not detected. The use of antibiotic was identified in 74 (87\%) patients in the 8 weeks prior to CDI diagnosis. (Table 1).

Toxigenic $C$. difficile strains were divided into four different PCR-ribotypes (012, 014, 017 and IR1) patterns. The most common ribotype was 014 accounting for $48.3 \%(7 / 15)$ of all toxigenic C.difficile isolates followed by the ribotypes $012(26.7 \%, 4 / 15)$ and $017(13.6 \%, 2 / 15)$ respectively. Three different sequence types (STs) identified based on MLST among the toxigenic isolates, ST54 $\left(n=5,33.3 \%, t c d A^{+}, t c d B^{+}, C D T^{-}\right), \mathrm{ST} 2(n=8,53.3 \%$, $\left.t c d A^{-}, t c d B^{+}, C D T^{-}\right)$, and ST37 $\left(n=2,13.6 \%, t c d A^{-}\right.$, $\left.t c d B^{+}, C D T^{-}\right)$. Strains isolated during the first episode and recurrence of CDI belonged to PCR ribotype 014 (ST2) (Additional file 1). A high rate of CDI recurrence $(14.1 \%, 12 / 85)$ experienced in UC patients. Clinical recurrences of CDI were diagnosed within one month of the antibiotic treatment. Among 85 patients, PCR ribotyping and MLST analysis showed C.difficile re-infection throughout the incident of UC. The most frequent 
isolates belonged to ribotype 014 (ST2). Two out of 12 patients $(17 \%)$ of studied patients were recognized re-infection by an identical strain of $C$. difficile (ribotype 014/ST2). Colonization of the gastrointestinal tract with non-toxigenic $C$. difficile strains (ribotype IR5, ST15, $\left.t c d A^{-}, t c d B^{-}, \mathrm{CDT}^{-}\right)$was frequent $(86.7 \%, 13 / 15)$ among patients with mild disease.

All C. difficile strains were susceptible to metronidazole (range 23-45 mm) and vancomycin (range 19-28 $\mathrm{mm}$ ). Only one isolate from a patient aged 60 with severe disease was resistant to fusidic acid, while the remaining isolates $(96.3 \%, 26 / 27)$ were susceptible to it (range 19-28 mm). Twenty four out of 27 patients (89\%) were susceptible to moxifloxacin (range 6-28 mm) and rifampin (range $23-45 \mathrm{~mm}$ ) while, 23 out of 27 isolates $(86 \%)$ were resistant to clindamycin, 18 out of 27 isolates (67\%) to erythromycin (median range 6-18 $\mathrm{mm}$ ). There was no correlation between the toxin type and antibiotic resistance $(p>0.05)$.

The stepwise multivariate logistic regression model revealed that patients who used steroids 8 weeks prior to testing for $C$. difficile were more than 6 times more likely to develop CDI than those who didn't (OR 6.03; 95\% CI, 4.6-38.5; $p=0.004$ ).

The study findings also revealed that patients with a history of previous surgery, anti-inflammatory treatment, and complicated UC were more likely to develop CDI (Table 2). We did not find a significant association between age, gender, colectomy, recent hospitalization and CDI in UC patients.

\section{Discussion}

Toxin-producing $C$. difficile strains are associated with worsening disease in UC patients. Recent decade studies have been shown a steady increase in CDI prevalence especially in UC patients [21, 23, 31]. The prevalence of CDI in UC patient in the present study was estimated as being $17.6 \%$. There are no systematic data to evaluate any increase/decrease of CDI prevalence in general and particularly in UC patients in Iran. However, the existing data from other countries indicate a significantly lower incidence of CDI $(2.8-11.1 \%)$ in adult UC patients compared to our findings $[17,32]$. Recent studies from Europe, Canada, and the United States suggesting a rate of $20-27 \%$ community-acquired CDI in the general population [33]. Other recent studies have reported that in the majority of IBD patients, CDI was contracted outside of the hospital and $47.2 \%$ of patients acquired CDI from the community [34]. Several factors may explain this higher rate including, patient population and sampling period. Fecal sampling for toxin detection was performed during a follow-up visit, which is regularly settled especially in the presence of worsening and we could detect more CDIs.

We found a significant relationship between the presence of CDI and steroid treatment, previous surgery, the severity of UC and anti-inflammatory treatment (Table 2). Previous studies have demonstrated that in UC patients, CDI is prevalent and colonic complicity, female, recent surgery, colectomy, younger age, and systemic steroid therapy was

Table 1 Clinical characterizations of 85 Ulcerative Colitis patients in CDI and Non CDI groups

\begin{tabular}{|c|c|c|c|c|c|}
\hline \multirow[t]{3}{*}{ Variables } & & \multirow{2}{*}{$\begin{array}{l}\text { CDI patients (15) } \\
\text { Toxigenic C.difficile strains, } \\
(A+B+\text { or } A-B+), n=15\end{array}$} & \multicolumn{2}{|c|}{ Non-CDI patients (70) } & \multirow{3}{*}{$\begin{array}{l}\text { Univariate } \\
\text { analysis } \\
P \text { value }\end{array}$} \\
\hline & & & \multirow{2}{*}{$\begin{array}{l}\text { Negative C.difficile } \\
\text { strains, } n=58 \\
\text { Count (\%) }\end{array}$} & \multirow{2}{*}{$\begin{array}{l}\text { Non toxigenic } \\
\text { strains, } n=12 \\
\text { Count (\%) }\end{array}$} & \\
\hline & & Count (\%) & & & \\
\hline Male & & $8(53.3)$ & $37(63.8)$ & $6(50)$ & 0.08 \\
\hline \multicolumn{6}{|l|}{ Severity of UC } \\
\hline Mild & & 0 & $38(65.5)$ & $11(91.7)$ & \\
\hline Moderate to severe & & $15(100.0)$ & $20(34.5)$ & $1(8.3)$ & 0.001 \\
\hline Previous surgery & & $10(66.7)$ & $16(27.6)$ & $6(50)$ & 0.02 \\
\hline \multirow{3}{*}{$\begin{array}{l}\text { Antibiotic treatment within } 8 \text { weeks prior } \\
\text { to CDI (metronidazole, Cyclosporine, } \\
\text { Clindamycin, cephalosporin, ...) }\end{array}$} & One & $4(26.7)$ & $18(31.0)$ & $3(25.0)$ & \multirow[t]{3}{*}{0.2} \\
\hline & Two & $6(40.0)$ & $18(31.0)$ & $4(33.3)$ & \\
\hline & Three & $5(33.3)$ & $12(20.7)$ & $4(33.3)$ & \\
\hline Steroids & & $15(100)$ & $20(34.5)$ & $4(33.3)$ & 0.001 \\
\hline \multirow[t]{2}{*}{ Anti-inflammatory drugs } & Mesalamine & $8(53.3)$ & $21(36.2)$ & $4(33.3)$ & \multirow[t]{2}{*}{0.01} \\
\hline & Sulfasalazine & $11(73.3)$ & $22(37.9)$ & $4(41.7)$ & \\
\hline History of colectomy & & $5(33.3)$ & $11(18.9)$ & $3(25.0)$ & 0.03 \\
\hline Age at diagnosis (years), mean \pm SD & & $46.5 \pm 11.4$ & $42.3 \pm 13.1$ & $41.2 \pm 14.3$ & 0.07 \\
\hline
\end{tabular}

Legends: UC ulcerative colitis, Mesalamine: 5-aminosalicylic acid (5-ASA), SD standard deviation 
Table 2 Multivariate logistic regression analysis for occurrence of C.difficile infection on UC patients

\begin{tabular}{lll}
\hline Risk factors & OR $(95 \% \mathrm{Cl})$ & $P$ value \\
\hline Steroid treatment & $6.03(4.6-38.5)$ & 0.004 \\
Previous surgery & $2.5(1.1-5.8)$ & 0.049 \\
Severity of UC & $2.9(1.9-23.8)$ & 0.011 \\
Anti-inflammatory drugs & $1.54(1.3-5.97)$ & 0.039 \\
\hline
\end{tabular}

Legends; OR Odds ratio, $\mathrm{Cl}$ Confidence interval

independently associated with CDI $[8,17,23,33-$ 35]. Fourteen percent of our patients showed one or two episodes of recurrences during the study period. Recurrence of CDI among UC patients is a fundamental problem and identification of CDI in early diagnosed UC may be beneficial because superimposed the management of CDI lead to clinical remission of UC [34]. Previous studies showed about 18 to $25 \%$ of IBD patients had experienced CDI recurrence within 30 days following treatment with metronidazole or vancomycin [31, 36]. Recurrences of $C$. difficile may be described either by the endogenous persistence of a $C$. difficile strain (relapse) or by contamination of a new strain from the environment (re-infection) [37]. About 17\% of studied patients in this study were recognized re-infection by an identical strain of $C$. difficile (ribotype 014/ST2). In other similar studies that performed in hospitalized patients, the rate of re-infection with identical strains was between 38 and $56 \%[8,21,37]$.

All identified C. difficile strains in our study showed susceptibility to vancomycin and metronidazole. Recurrence CDI has been observed in patients that had taken metronidazole. Other similar studies showed that patients with an IBD flare and concurrent CDI treated with vancomycin had successful treatment and vancomycin is the first-choice therapy for moderate to severe CDI $[17,23]$. Most studies have exhibited that certain antibiotics such as clindamycin, moxifloxacin, and fluoroquinolones carry a higher risk for CDI. Low susceptibility to these antimicrobial agents has been reported in other studies that can be attributed to different antibiotic regimens used [38, 39]. There was no significant difference in the resistance rates between CDI and non-CDI patients with respect to their susceptibility to these antibiotics (Fig. 1). Hypervirulent Ribotype 027 (ST1) also was not found in the present study, nor was ribotype 078 (ST11), based on inference of the lack of $c d t A / c d t B$ genes in any isolate and MLST analysis. We have previously reported ribotype 078 as a common strain in both humans and meat in Iran so the absence of this strain in the current study was surprising. $[4,40]$. Most of CDI in the current study were found to be due to $\mathrm{A}^{-} \mathrm{B}^{+}$strains (ST2, ST37). Recent studies have reported an increasing number of infections due to $\mathrm{A}^{-} \mathrm{B}^{+}$ strains especially ST37 in Asia although such strains do not produce a binary toxin [41].

In the previous report from Southern India, nontoxigenic $C$. difficile strains identified in a significantly high rate of $90 \%$ of UC patients and about $55 \%$ of healthy subjects [21]. We found an overgrowth of nontoxigenic C. difficile intestinal carriage of the much lower rate in 12 patients $(14.2 \%)$ of studied patients. Its relatedness to disease pathogenesis and severity in a contaminated environment justifies further investigations.

There are several limitations to our study including small sample size, which have led to underestimating the true prevalence and diversity of circulating $C$. difficile strains and lack of a healthy control group to be compared with the UC patients. This is the first study provides information about different aspects of molecular epidemiology, clinical characteristics, and antibiotic resistance profiles of circulating $C$. difficile strains among Iranian patients with ulcerative colitis. Further research and clinical studies with a larger population should be performed to evaluate the epidemiology of $C$. difficile in this high-risk group.

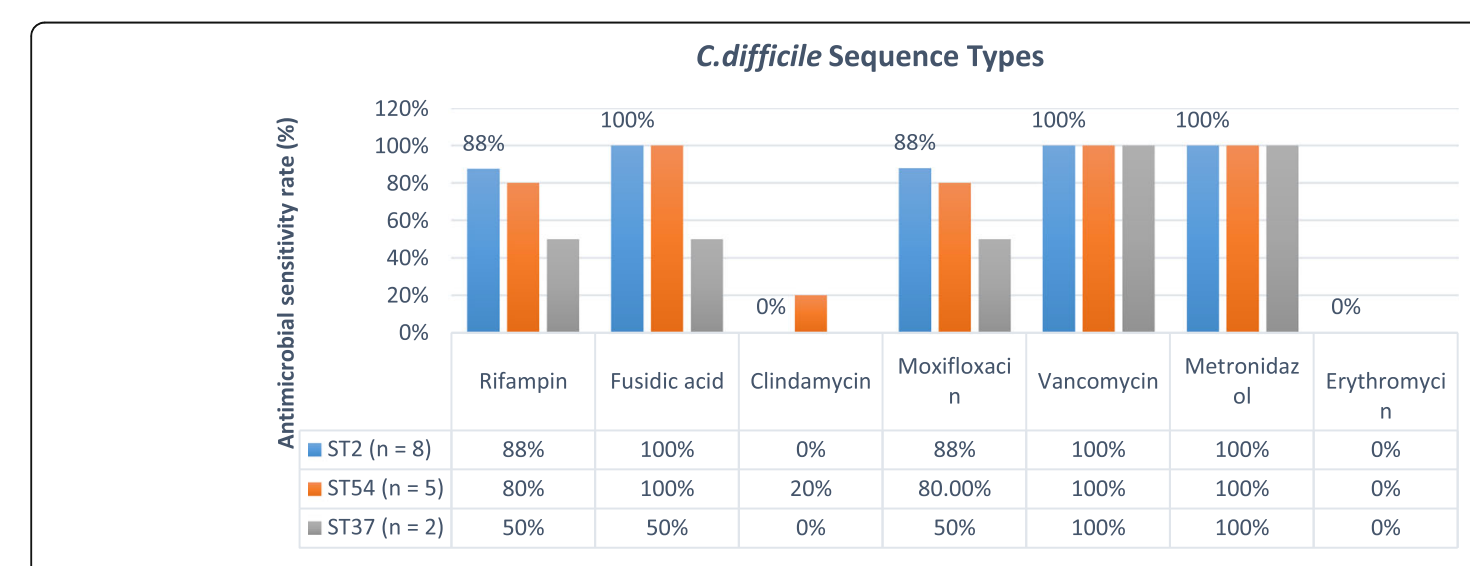

Fig. 1 Antimicrobial sensitivity rates among different STs of toxigenic C. difficile isolates. Legends: ST, sequence type 


\section{Conclusion}

Overall, CDI is rather prevalent in UC. All patients with CDI experienced moderate to severe disease and exposed to different antimicrobial and anti-inflammatory agents. Close monitoring and appropriate management including early detection and fast treatment of CDI will improve UC outcomes.

\section{Additional file}

Additional file 1: Normalized dendrogram of the detected isolates of C.difficile, PCR- ribotyping fingerprints with the primers 16S-23S. Similarity coefficients are included in the top bar; Dendrogram is color-coded according to sequence types (STs) and toxin types. The similarity was calculated using the Dice coefficient and UPGMA clustering. (DOCX $951 \mathrm{~kb}$ )

\section{Abbreviations}

UC: Ulcerative colitis; IBD: Inflammatory bowel disease; CDI: Clostridium difficile infection; MLST: Multilocus sequence typing analysis; CDMN: C. difficile moxalactam norfloxacin; ST: Sequence type

\section{Acknowledgments}

The authors would like to express their gratitude to the Prof Peyman Adibi for the conception of the design of the work and Mr. Abbas Daei Naser and Mrs. Rezvan Shafiei for their contributed in the experimental studies.

\section{Funding}

A part of this article (MLST analysis) is extracted from research (grant number 291234) that performed in the Infectious Disease Research center, Isfahan University of medical sciences, Isfahan, Iran.

\section{Availability of data and materials}

The data analysed during the current study available from the corresponding author on reasonable request.

\section{Authors' contributions}

SH P contributed in the experimental studies, and drafting the work, Kh F and $\mathrm{BA}$ contributed in the conception of design, $\mathrm{E} F$ and $\mathrm{VB}$ and $\mathrm{E} Z$ contributed in the acquisition of the data. T H, J M, W JS, and SH H contributed in the conception of design and revising the draft, H SM contributed in the analysis of the data. All authors read and approved the final manuscript.

\section{Ethics approval and consent to participate}

The Ethics Committee on Clinical Investigation of the Isfahan University of Medical Sciences, Isfahan, Iran, approved this presented research. Written consent informed was obtained from all participants.

\section{Consent for publication}

Not applicable.

\section{Competing interests}

The authors declare that they have no competing interests.

\section{Publisher's Note}

Springer Nature remains neutral with regard to jurisdictional claims in published maps and institutional affiliations.

\footnotetext{
Author details

${ }^{1}$ Nosocomial Infection Research Center, Isfahan University of Medical Sciences, Isfahan, Iran. ²Department of Microbiology, School of Medicine, Isfahan University of Medical Sciences, Isfahan, Iran. ${ }^{3}$ School of Food Science and Nutrition, Isfahan University of Medical Sciences, Isfahan, Iran. ${ }^{4}$ Epidemiology and biostatics department, Isfahan University of Medical sciences, Isfahan, Iran. ${ }^{5}$ Infectious Diseases and Tropical Medicine Research Center, Isfahan University of Medical Sciences, Isfahan, Iran. ${ }^{6}$ Department of Microbiology, Science and Research Branch, Islamic Azad University, Tehran,
}

Iran. ${ }^{7}$ Department of Microbiology, Islamic Azad University of Falavarjan, Isfahan, Iran. ${ }^{8}$ Department of Physiology and Pathophysiology, University of Manitoba, Winnipeg, MB, Canada. ${ }^{9}$ Department of Research and Development, Vice Chancellory for food and drug, Isfahan, Iran.

${ }^{10}$ Department of Pathobiology and Centre for Public Health and Zoonoses, Ontario Veterinary College, University of Guelph, Guelph, Canada.

Received: 3 August 2018 Accepted: 8 April 2019

Published online: 30 April 2019

\section{References}

1. Hourigan SK, Oliva-Hemker M, Hutfless S. The prevalence of Clostridium difficile infection in pediatric and adult patients with inflammatory bowel disease. Dig Dis Sci. 2014;59(9):2222-7. https://doi.org/10.1007/s10620-0143169-4.

2. Martin H, Willey B, Low DE, Staempfli HR, McGeer A, Boerlin P, Mulvey M, Weese JS. Characterization of Clostridium difficile strains isolated from patients in Ontario, Canada, from 2004 to 2006. J Clin Microbiol. 2008;46(9): 2999-3004. https://doi.org/10.1128/JCM.02437-07.

3. Bidet $P$, Barbut F, Lalande V, Burghoffer B, Petit JC. Development of a new PCR-ribotyping method for Clostridium difficile based on ribosomal RNA gene sequencing. FEMS Microbiol Lett. 1999;175(2):261-6.

4. Jalali M, Khorvash F, Warriner K, Weese JS. Clostridium difficile infection in an Iranian hospital. BMC Res Notes. 2012;5(1):159. https://doi.org/10.1186/ 1756-0500-5-159.

5. Griffiths D, Fawley W, Kachrimanidou M, Bowden R, Crook DW, Fung R, Golubchik T, Harding RM, Jeffery KJ, Jolley KA, Kirton R, Peto TE, Rees G, Stoesser N, Vaughan A, Walker AS, Young BC, Wilcox M, Dingle KE. Multilocus sequence typing of Clostridium difficile. J Clin Microbiol. 2010; 48(3):770-8. https://doi.org/10.1128/JCM.01796-09.

6. Lemee L, Dhalluin A, Pestel-Caron M, Lemeland J-F, Pons J-L. Multilocus sequence typing analysis of human and animal Clostridium difficile isolates of various toxigenic types. J Clin Microbiol. 2004;42(6):2609-17.

7. Stabler RA, Dawson LF, Valiente E, Cairns MD, Martin MJ, Donahue EH, Riley TV, Songer JG, Kuijper EJ, Dingle KE, Wren BW. Macro and microdiversity of Clostridium difficile isolates from diverse sources and geographical locations. PLoS One. 2012;7(3):e31559. https://doi.org/10.1371/journal.pone. 0031559.

8. Negrón ME, Rezaie A, Barkema HW, Rioux K, De Buck J, Checkley S, Beck PL, Carroll M, Fedorak RN, Dieleman L. Ulcerative colitis patients with Clostridium difficile are at increased risk of death, colectomy, and postoperative complications: a population-based inception cohort study. Am J Gastroenterol. 2016;111(5):691.

9. Nguyen GC, Kaplan GG, Harris ML, Brant SR. A national survey of the prevalence and impact of Clostridium difficile infection among hospitalized inflammatory bowel disease patients. Am J Gastroenterol. 2008;103(6):1443.

10. Berg AM, Kelly CP, Farraye FA (2012) Clostridium difficile infection in the inflammatory bowel disease patient. Inflammatory bowel diseases.

11. MCDonald LC, Gerding DN, Johnson S, Bakken JS, Carroll KC, Coffin SE, Dubberke ER, Garey KW, Gould CV, Kelly C. Clinical practice guidelines for Clostridium difficile infection in adults and children: 2017 update by the Infectious Diseases Society of America (IDSA) and Society for Healthcare Epidemiology of America (SHEA). Clin Infect Dis. 2018;66(7):e1-48.

12. Sinh $P$, Barrett TA, Yun L. Clostridium difficile infection and inflammatory bowel disease: a review. Gastroenterol Res Pract. 2011;2011:136064. https:// doi.org/10.1155/2011/136064.

13. Joshi NM, Marks IH, Crowson R, Ball D, Rampton DS. Incidence and outcome of Clostridium difficile infection in hospitalized patients with inflammatory bowel disease in the UK. J Crohns Colitis. 2017;11(1):70-6. https://doi.org/10.1093/ecco-jcc/jjw117.

14. Banaszkiewicz A, Kowalska-Duplaga K, Pytrus T, Pituch H, Radzikowski A. Clostridium difficile infection in newly diagnosed pediatric patients with inflammatory bowel disease: prevalence and risk factors. Inflamm Bowel Dis. 2012:18(5):844-8. https://doi.org/10.1002/ibd.21837.

15. Ricciardi R, Ogilvie JW Jr, Roberts PL, Marcello PW, Concannon TW, Baxter $\mathrm{NN}$. Epidemiology of Clostridium difficile colitis in hospitalized patients with inflammatory bowel diseases. Dis Colon rectum. 2009;52(1):40-5. https://doi. org/10.1007/DCR.0b013e31819733fd.

16. Vindigni SM, Surawicz CM. C. difficile infection: changing epidemiology and management paradigms. Clin Transl Gastroenterol. 2015;6(7):e99. https://doi. org/10.1038/ctg.2015.24. 
17. D'Aoust J, Battat R, T B. Management of inflammatory bowel disease with Clostridium difficile infection. 2017;23(27):4986.

18. Surawicz CM, Brandt $L$, Binion DG, Ananthakrishnan AN, Curry SR, Gilligan PH, McFarland LV, Mellow M, BS Z. Guidelines for diagnosis, treatment, and prevention of Clostridium difficile infections. 2013;108(4):478.

19. Escher J. Inflammatory bowel disease in children and adolescents: recommendations for diagnosis-the Porto criteria. J Pediatr Gastroenterol Nutr. 2005;41(1):1-7.

20. Rodriguez-Palacios A, Stampfli HR, Duffield T, Peregrine AS, Trotz-Williams LA, Arroyo LG, Brazier JS, Weese JS. Clostridium difficile PCR ribotypes in calves, Canada. Emerg Infect Dis. 2006;12(11):1730-6. https://doi.org/10. 3201/eid1211.051581.

21. Jodorkovsky D, Young Y, Abreu MT. Clinical outcomes of patients with ulcerative colitis and co-existing Clostridium difficile infection. Dig Dis Sci. 2010;55(2):415-20. https://doi.org/10.1007/s10620-009-0749-9.

22. Cooney RM, Warren BF, Altman DG, Abreu MT, Travis SP. Outcome measurement in clinical trials for ulcerative Colitis: towards standardization. Trials. 2007:8(1):17. https://doi.org/10.1186/1745-6215-8-17.

23. Garcia PG, Chebli LA, da Rocha Ribeiro TC, Gaburri PD, de Lima Pace FH, Barbosa KVBD, Costa LA, de Almeida Cruz W, de Assis IC, Moraes BRMJljocd (2018) Impact of superimposed Clostridium difficile infection in Crohn's or ulcerative colitis flares in the outpatient setting.1-10.

24. Lemee L, Dhalluin A, Testelin S, Mattrat MA, Maillard K, Lemeland JF, Pons JL. Multiplex PCR targeting tpi (triose phosphate isomerase), tcdA (toxin a), and tcdB (toxin B) genes for toxigenic culture of clostridium difficile. J Clin Microbiol. 2004;42(12):5710-4. https://doi.org/10.1128/JCM.42.12.5710-5714.2004.

25. Bouillaut L, McBride SM, Sorg JA (2011) Genetic manipulation of Clostridium difficile. 20 (1):9A. 2.1-9A. 2.17.

26. Pitcher D, Saunders N, Owen R. Rapid extraction of bacterial genomic DNA with guanidium thiocyanate. Lett Appl Microbiol. 1989;8(4):151-6.

27. Stubbs S, Rupnik M, Gibert M, Brazier J, Duerden B, Popoff M. Production of actin-specific ADP-ribosyltransferase (binary toxin) by strains of Clostridium difficile. FEMS Microbiol Lett. 2000;186(2):307-12. https://doi.org/10.1111/j. 1574-6968.2000.tb09122.x.

28. Rodemann JF, Dubberke ER, Reske KA, Seo DH, Stone CD. Incidence of Clostridium difficile infection in inflammatory bowel disease. Clin Gastroenterol Hepatol. 2007;5(3):339-44. https://doi.org/10.1016/j.cgh.2006. 12.027.

29. Fraga EG, Nicodemo AC, Sampaio $J$ (2016) Antimicrobial susceptibility of Brazilian Clostridium difficile strains determined by agar dilution and disk diffusion. 20 (5):476-481.

30. Erikstrup LT, Danielsen T, Hall V, Olsen K, Kristensen B, Kahlmeter G, Fuursted K, Justesen US. Antimicrobial susceptibility testing of Clostridium difficile using EUCAST epidemiological cut-off values and disk diffusion correlates. Clin Microbiol Infect. 2012;18(8):E266-72.

31. Navaneethan $U$, Venkatesh PG, Shen B. Clostridium difficile infection and inflammatory bowel disease: understanding the evolving relationship. World J Gastroenterol. 2010;16(39):4892-904

32. Kim DB, Lee K-M, Park SH, Kim YS, Kim ES, Lee J, Jung S, Seo GS, JMJIr L. Is Clostridium difficile infection a real threat in patients with ulcerative colitis? A prospective, multicenter study in Korea. 2018;16(2):267-72.

33. Gillespie W, Marya N, Fahed J, Leslie G, Patel K, Cave DR, Practice (2017) Clostridium difficile in inflammatory bowel disease: a retrospective study. 2017.

34. Kariv R, Navaneethan U, Venkatesh PG, Lopez R, Shen B. Impact of Clostridium difficile infection in patients with ulcerative colitis. J Crohns Colitis. 2011;5(1):34-40. https://doi.org/10.1016/j.crohns.2010.09.007.

35. Ben-Horin S, Margalit M, Bossuyt P, Maul J, Shapira Y, Bojic D, Chermesh I, Al-Rifai A, Schoepfer A, Bosani M, Allez M, Lakatos PL, Bossa F, Eser A, Stefanelli T, Carbonnel F, Katsanos K, Checchin D, Miera IS, Chowers Y, Moran GW, Cs E, Colitis O. Combination immunomodulator and antibiotic treatment in patients with inflammatory bowel disease and Clostridium difficile infection. Clin Gastroenterol Hepatol. 2009;7(9):981-7. https://doi org/10.1016/j.cgh.2009.05.031

36. Issa M, Ananthakrishnan AN, Binion DG. Clostridium difficile and inflammatory bowel disease. Inflamm Bowel Dis. 2008;14(10):1432-42. https://doi.org/10.1002/ibd.20500.

37. Barbut F, Richard A, Hamadi K, Chomette V, Burghoffer B, Petit J-C. Epidemiology of recurrences or reinfections ofClostridium difficile-associated diarrhea. J Clin Microbiol. 2000;38(6):2386-8.

38. Goudarzi M, Goudarzi H, Alebouyeh M, Azimi Rad M, Shayegan Mehr FS, Zali MR, Aslani MM. Antimicrobial susceptibility of Clostridium difficile clinical isolates in Iran. Iran Red Crescent Med J. 2013;15(8):704-11. https:// doi.org/10.5812/ircmj.5189.

39. Wang R, Suo L, Chen HX, Song LJ, Shen YY, Luo YP. Molecular epidemiology and antimicrobial susceptibility of Clostridium difficile isolated from the Chinese People's Liberation Army General Hospital in China. 2018; 67:86-91.

40. Rahimi $\mathrm{E}$, Jalali M, Weese JS. Prevalence of Clostridium difficile in raw beef, cow, sheep, goat, camel and buffalo meat in Iran. BMC Public Health. 2014; 14(1):119. https://doi.org/10.1186/1471-2458-14-119.

41. Chen Y-B, Gu S-L, Wei Z-Q, Shen P, Kong H-S, Yang Q, Li LJ. Molecular epidemiology of Clostridium difficile in a tertiary hospital of China. 2014; 63(4):562-9
Ready to submit your research? Choose BMC and benefit from:

- fast, convenient online submission

- thorough peer review by experienced researchers in your field

- rapid publication on acceptance

- support for research data, including large and complex data types

- gold Open Access which fosters wider collaboration and increased citations

- maximum visibility for your research: over $100 \mathrm{M}$ website views per year

At $\mathrm{BMC}$, research is always in progress.

Learn more biomedcentral.com/submissions 